\title{
Expanding educational chronotopes with personal digital devices
}

\author{
Øystein Gilje, ILS, UiO.
}

Pre-print draft.

Gilje, $\varnothing$. (2019). Expanding educational chronotopes with personal digital devices. Learning, Culture and Social Interaction, 21, 151-160.

\begin{abstract}
The aim of this study is to investigate the role of personal digital devices for negotiating assignments during collaborative work in school. Using video recordings of the peer-to-peer interactions in two math and Norwegian language projects, an interactional analysis (IA) is used to analyse the meaning making and the role of phones and cameras in social interaction. To enable a better understanding of the spatial and temporal dimensions in the school context, the students' interactions with the digital devices are used as the unit of analysis because these interactions constitute a practice 'in tandem' with the cultural tools and mediational means being deployed. Using two cases, the article demonstrates how personal digital devices can constitute and reconstitute the spatial and temporal dimensions in the educational chronotope. Overall, the findings show the ways in which the specific features of the screen and viewfinder are important in understanding the dialogues and negotiations during collaborative work on assignments where students use personal digital devices.
\end{abstract}




\section{Introduction}

In the twenty-first century, school activities are still structured in the spatial and temporal dimensions in particular ways (Jackson, 1990; Lemke, 2000; Rajala, 2016); schooling is a specific practice of learning in context structured by scheduled lectures and designated spaces in which agents use specific tools for educational purposes (Hamilton \& Zufiaurre, 2014, pp. 132137; Säljö, 2000). As Matusov noted, 'The teacher and the students are usually present simultaneously in the ontological time-space of their classroom' (2015, p. 68).

There is growing interest in theoretical conceptualisations of time-space that use the Bakhtinian term 'chronotope' when analysing how schooling is organised in these dimensions (Matusov, 2015; Ritella, Ligorio, \& Hakkarainen, 2017), examining schools' literacy practices (ComptonLilly \& Halverson, 2014; Leander \& Sheehy, 2004; Skaftun, Igland, Husebø, Nome, \& Nygard, 2017) and exploring students' agency and identity (Holland, Lachicotte Jr., Skinner, \& Cain, 1998; Leander, 2002). Thus, the chronotope concept has been deployed in analytical work for a number of reasons and with different analytical purposes.

The current article aims at elaborating on a branch of these studies that focus on technology by analysing how educational spaces are constituted and reconstituted when students bring their own technology into the school context. In line with the theme of this special issue, the analysis is framed by the following research question: How do agents constitute and reconstitute an educational chronotope with their personal smartphones and SLR cameras? Here, the argument is that a chronotopic analysis enables a better understanding of the relationship between the material, social and semiotic level as students deploy their personal digital devices for specific 
purposes to solve assignments in school. Such a perspective is important as it contains descriptive (in use) and prescriptive (espoused) power (Matusov, 2005)

The present article consists of the following: Section 2 is a conceptual review of the term 'chronotope' in educational studies, here looking specifically at research that scrutinises the use of digital technology. Section 3 reviews the role of digital technology in school with a specific emphasis on mobile phones. Section 4, which discusses the method and analyses used, explains the data and analytical account of the interactional analysis (IA); to enhance the analysis of the two cases, video data were used to scrutinise students' activities in two diverse educational settings. Section 5 discusses how digital technology allows students to reconstitute educational chronotopes, and the implications of the study are discussed in relation to teaching.

\section{Theoretical perspectives}

For over two decades, educational researchers have investigated learning contexts and sites as part of their unit of analysis (Bliss, Säljö, \& Light, 1999; Hamilton \& Zufiaurre, 2014; Lemke, 2000; Ludvigsen, Lund, \& Rasmussen, 2010). A specific critique of 'traditional' schooling is also found in the discourse analysis of educational contexts and new media (Gee, 2004; Leander, 2001). Moreover, educational ethnographies have acknowledged the materiality of education (Nespor, 1997) in studies that draw on concepts developed in science and technology studies (Knorr-Cetina, 1999), the same as with actor-network theory, which considers humans and nonhumans to be equal participants in social processes (Fenwick \& Edwards, 2010, 2012; Sørensen, 2009). Roehl (2012) pointed out that these authors argue that material objects contribute 'to education not only as semiotic carriers of meaning but as non-human actors, that is, as entities that profoundly shape school lessons and other sites of education' (p.112). Hence, a 
chronotopic analysis provides an alternative to the studies that have explored materiality and digital devices in the classroom.

A chronotopic analysis enables scholars to investigate how time and space work together to shape participation in a specific educational context (Brown \& Renshaw, 2006; Lemke, 2000; Matusov, 2015; Renshaw, 2017). A specific branch of these studies focuses on the communicative practices in chronotopes and in how space and time are organised by agents in social interaction and their use of digital cultural tools and mediational means (Kumpulainen, Mikkola, \& Jaatinen, 2013; McLay, Renshaw, \& Phillips, 2016; Ritella et al., 2017). However, there seems to be a broad spectrum regarding how the concept 'chronotope' and 'chronotopic analysis' are used (Matusov, 2015; Ritella, 2018; Ritella, Rajala, \& Renshaw, in review).

Matusov (2015) made an important distinction by dividing between a chronotopic analysis, which can enable the understanding of (1) classroom interactions at moments in the historical past (cf. Renshaw, 2014) and (2) the use of the concept to unite both the material and ideological conditions, hence shaping a specific practice that can be studied in situ. The current article elaborates on this latter perspective by analysing the interactional aspect of sense-making: 'through tracking both participants' moves in the here and now of the semiotic process and the dynamic, situational organization of the physical and virtual space-time on a micro level' (Ritella \& Ligorio, 2016, p. 224).

In his summary of the use of chronotopes in research on learning, Ritella (2018) distinguished between four different types of analytical purposes for studies of space and time: (1) the organisation and moving of objects, bodies and technologies; (2) the discursive negotiation of space and time; (3) the organisation of meanings; and (4) the development of the 'self' (Ritella, 
2018, p. 41.). The first group of studies is particularly interesting because this group focuses on how 'school rhythms' and classrooms and tasks are organised (Matusov, 2009), along with how digital technology can trigger 'the emergence of new chronotopes' (Ritella, 2018, p. 41). This perspective on a chronotopic analysis allows for an explanation of the variations in the pace and emerging organisation of an activity. A chronotopic analysis of the organisation and moving of objects, bodies and technologies in space and time provides a specific lens with which to view how digital technology devices transform the space-time relationship in educational contexts (Erstad, 2014; Kumpulainen, Mikkola, \& Jaatinen, 2014; Ritella, Ligorio, \& Hakkarainen, 2016; Skaftun et al., 2017). The findings and perspectives of these studies can be considered attempts to disrupt 'container-like visions of social spaces of learning' (Leander, Phillips, \& Taylor, 2010, p. 335) because they illustrate how different ways of organising school learning provide students with various opportunities and constraints when the students act within the social, semiotic and material worlds.

\section{Personal digital devices invading educational contexts}

In the last two decades, digital technology has been organised and used in different ways in lower and upper secondary schools, and researchers have looked at the rationales behind implementing digital technology and the various ways it has been used (Hammond, 2014; PérezSanagustín et al., 2017; Selwyn, 2015). Many schools keep their devices on trolleys or in specific data labs; in these schools, the teachers' organisation of time and space grants the students access to digital technology during designated, planned lessons for which the PCs are moved into the classroom or the pupils move to the data lab. In the present article, data labs are understood as institutionalised spaces with the infrastructure needed to support learning. 
The chronotopic analysis in the current article concerns the students' personal digital devices. On a sociogenetic level, mobile phones and digital cameras can be considered as boundary objects (Akkerman \& Bakker, 2011; Star \& Griesemer, 1989) because they cross a boundary between how time and space are organised outside school and how school is organised in specific lessons and assignments. As highlighted in a number of studies and in the current public debate surrounding the use of these devices, there are tensions related to the presence of students' personal digital technology in school.

In his thesis on the use of mobile phones in upper secondary schools, Ott (2017) pointed out that boundary objects can 'have similarities with mediational means (Wertsch, 1998) or mediational artefacts (Säljö, 2000)'. In their discussion of the smartphone as a boundary object, Ott Haglind and Lindström (2014) argued that 'Boundary objects are objects of interpretive flexibility and objects of action. A boundary object resides between social worlds where it is poorly structured' (p. 71). Herein, the understanding of at boundary object is in line with that of Star, who called it a 'shared space, where exactly that sense of here and there are confounded' (2010, pp. 602-603). In many cases, bringing a smartphone into the practice of learning in school crosses a boundary (and opens the container) because the phone is not a part of how schools organise objects and technologies in time and space. In this sense, a chronotopic analysis provides a lens for how students constitute and reconstitute the educational chronotope when they are bringing their own personal digital devices to act on the social, semiotic and material world.

Although we know something about the use of laptops and iPads in Norwegian schools, we know less about how mobile phones and personal digital devices are used in educational contexts. The data from surveys conducted in Norway showed that 9 out of 10 children age 9-16 had strict rules governing their use of mobile phones (Medietilsynet, 2016). In addition, 
international research on students' and teachers' perceptions of smartphones has shown that mobile phones give students the opportunity to 'breathe' during the busy school day by using their phone in class 'spaces', either during or between classes (Sahlström, Tanner, \& Valasmo, 2017; Takahashi, 2011). Regarding lessons, Ott et al. (2014) stated, 'The structure of school tasks and the tools that are supposed to be used in working with them are set. The mobile phone does not belong to the primary repertoire of tools to be used' (p. 72). Other studies have found that students use mobile phones spontaneously to search for information (Gilje \& Silseth, 2017), store photos and take notes, but they also use them to communicate with others or check social media (Ott et al., 2014). In sum, previous research has shown that the use of mobile phones outside and inside of secondary school classes varies widely in both scope and practice. The contrast between phone use inside and outside of school is greater in lower secondary compared

to upper secondary schools, which may have more liberal practices. Gilje and Silseth (2017) pointed out that the smartphone is perceived differently in some school projects like 'fagdag' and that digital technology may be integrated in better ways these days. This finding is the point of departure for the current study, which aims to analyse how educational chronotopes are constituted when students bring their personal digital technology to solve the tasks of specific assignments.

\section{Fieldwork, method, data and analytical procedures}

\subsection{Fieldwork, method and data}

The data in the current paper stem from a 3-year ethnography - Knowledge in Motion - of nearly 100 pupils in two lower secondary schools in southeast Norway. The project Knowledge in Motion aims to understand how knowledge travels on and across the boundaries between out-of- 
school activities (including sports and media use) and school activities and learning (cf. Erstad \& Smette, 2017; Silseth, 2018; Silseth \& Gilje, 2017; Stefansen, Smette, \& Strandbu, 2016; Strandbu, Stefansen, Smette, \& Sandvik, 2017; Wiig, Silseth, \& Erstad, 2017). During the course of the fieldwork for Knowledge in Motion, both schools banned the use of phones. However, for a few days each semester, the students were allowed to use personal digital devices for particular assignments that lasted either for several hours or a full day, the latter of which was called a 'fagdag' (subject day). We video-recorded sessions of collaborative activity on these days in addition to the recordings of classroom interactions during 'traditional' lessons, which is not part of the data in this article. The current article analyses the video data of the social interactions from one of the two schools in the research project. In this school, there were two different projects, on two specific days, that were differently structured in terms of time and the organisation of activities compared to the other lessons. In addition to these video data, the fieldwork conducted over several semesters yielded other types of data, including a questionnaire about media use and sport in the leisure time $(\mathrm{n}=87)$ media diaries and artefacts ('screenographies', see Section 5) created by the pupils $(\mathrm{n}=85)$. These data types provide an ethnographic account that enable an understanding of 'digital engagement' in general (Deng, Connelly, \& Lau, 2016) and an understanding of how students use and perceive their mobile phones in 'out-of-school' media ecologies in particular (Horst \& Miller, 2012; Ito et al., 2010). The term 'media ecologies' extends the understanding of this concept in communication studies (cf. McLuhan, 1994; Meyrowitz, 1986) by focusing on 'the structure and context of media use' (Ito et al., 2010, p. 31). Although the terms media ecology and chronotope seem to show a shared focus on the structuring of time and space, there has only been a few attempts to discuss the relation between these two terms in educational research (Erstad, 2014, pp. 10-13) and as 
Frølunde stated (2012) in discussions on authorship as 'complex sociocultural-historical network, made up of a variety of networks and meanings that evolve within a media ecology' ( $p$. 492). It is beyond the scope of the current paper to further discuss the conceptual relationship between media ecology and chronotope, but the terms will be referred to in the first descriptive sociogenetic analysis of technology use in the educational context and the use of media out of school.

\subsection{Methodological considerations and analytical procedures}

To further develop a chronotopic analysis, the unit of analysis must first be discussed. Ritella and Ligorio (2016) divided between a macro, meso and micro level in a chronotopic analysis, where the micro level enables us to scrutinise the dynamic movements of bodies and artefacts during conversations. Taking the micro level as a point of departure for the chronotopic analysis, there is a need to discuss the methodological foundation for the chronotopic analysis that is used in Section 6.1 and 6.2. In their article on the unit of analysis in a chronotopic analysis, Ritella et al. (in review) sketched out four principles for creating a methodological foundation; one of these principles emphasises how the chronotopic analysis can reveal the relationship between the material, social and semiotic aspects of space-time (Ritella et al., in review). Studies that emphasise this interconnectedness define chronotopes as "the organization of the space-time frames in sense-making, emerging movements between space-time frames in discursive interactions (...) and as the material organization of bodies and objects' (Ritella \& Ligorio, 2016, p. 223). 
To further the understanding of students' sense-making in collaborative talk in a chronotopic analysis on a micro level, the examination of chosen excerpts takes an IA as its foundation (Jordan \& Henderson, 1995). Although a conversational analysis (CA) enables researchers to understand the basic organisational unit of the conversational turn (Sacks, Schegloff, \& Jefferson, 1974), an IA analyses 'the ways in which participants utilise the resources of the complex social and material world of actors and objects within which they operate' (Jordan \& Henderson, 1995, p. 41). Two aspects of an IA are particularly important when it comes to the microgenetic analysis discussed herein. First, a decisive premise in an IA is that knowledge and action must be grounded in empirical evidence, that is, in verifiable observations of moment-tomoment verbal and nonverbal activities in social settings. Second, an IA emphasises how the participants in the interaction engage with the digital devices as objects and artefacts in both the verbal and nonverbal activities, as well as in their bodily movements. This perspective allows for an explanation of the variations in the pace and emerging organisation of an activity. IA offers an analytical account for a chronotopic analysis that focus on the organisation and moving of objects, bodies and technologies in space and time.

In the present study, the transcripts are based on video data, and the pictures are rendered to make the students' faces unrecognisable. In addition, the pictures are cropped and enlarged to emphasise the digital devices in use. In regard to the ethical protocols, the students gave their consent to be video recorded in the sessions, and all the students have given their consent to use these rendered pictures for this article.

\section{The school as an educational chronotope}


This section focuses on the typical configuration of space and time that characterise the studied school. The aim of this ethnographic introduction is to describe the educational context on a sociogenetic level before analysing the interactional data on a microgenetic level in situ (Gilje, 2010; Wertsch, 1985a, 1985b). Throughout our 3 years of fieldwork, we observed little use of ICT during teaching hours and virtually no use of mobile phones. The mobile ban was equally and largely enforced by all teachers at both schools, and in our fieldwork, we observed phones being collected in a big plastic box at the beginning of the school day (see figure 1).

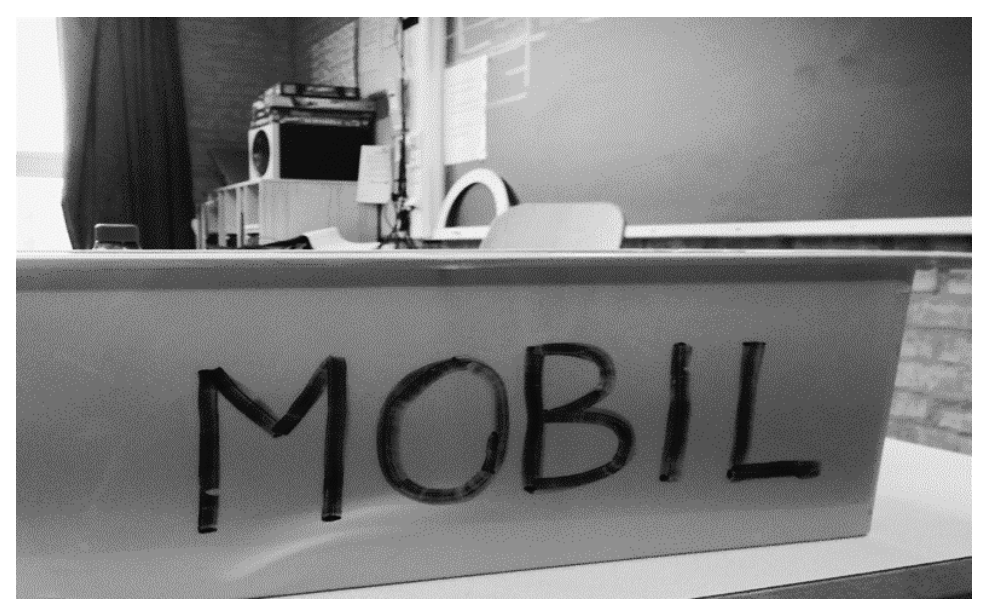

Figure 1. Plastic box for collecting phones at the beginning of the day.

During regular lessons, the students accessed PCs in two ways: either all the students moved to the data lab, or the laptops were brought to the classroom on a heavy-duty trolley. Both the data lab and the PC trolleys had to be booked in advance, meaning that they had to be planned in detail. Our analysis of the students' use of digital devices outside of school (cf. Gilje \& Silseth, in preparation; Gilje \& Silseth, 2017) revealed a media ecology with unlimited access to digital devices. As pointed out in the methods section, we used 'screenographies', media diaries and timelines to understand the students' investments in new media activities (Gilje, 2016). In this 
out-of-school context, only PCs - not phones or tablets - were used to work with homework, as illustrated with this common description of the use of screens (Figure 1). ${ }^{1}$



Figure 2. Example of a 'screenography' produced by a student.

In sum, the findings from the fieldwork revealed a large contrast between the use and role of digital devices outside school and in school, where students arrived in the morning and attended four to six different classes that had only occasional PC use (cf. Gilje \& Silseth, 2017; Silseth \& Gilje, 2017). To understand how the 'fagdag' as an educational chronotope contrasted the traditional structuring of time, space and technology, the following fieldnote from the start of a 'fagdag' serves as an introduction:

At the beginning of the day, at 08.34 , the assignment for the day was given to the students, and the teacher focused on the task: make a movie based on a chapter in the the textbook. He (the teacher) divided the students into groups based on his knowledge of each pupil and based on access to the machines and photo devices and possibly to the tripod. Last week, he distributed a form on which the students could describe their knowledge, devices and competence regarding movie-making. The school has only four cameras, and

\footnotetext{
${ }^{1}$ Although access to PCs and phones was restricted, the PC played an important role for students working on school assignments at home. Part of the questionnaire asked students about their use of phones and the Internet while doing homework. More than $60 \%$ said they needed a PC to do homework and would not be able to do their homework without the Internet.
} 
the teacher does not know their condition. Each group is equipped with digital equipment, like PC with editing software, digital camera and phones.

Field note, Sørlia, 1 November 2014

On days where students were allowed to use their personal, digital devices, the students were divided into groups, each of which planned its own use of digital technology and the distribution of its work, as indicated in the above field note. Two points should be made here. First, the digital technology that the students possessed crossed boundaries because the digital devices moved from the students' media ecologies outside of school to school to be used for specific assignments. As the teacher divided the students into groups based partly on the students' competences, the students with more competencies were positioned as important to completing these assignments. By doing this, the students' digital devices, but also their competencies in using these devices for shooting and editing, were included in the educational context. The following two cases show how these material devices and students' meaning-making in using their personal devices constitute and reconstitute the educational chronotope.

\section{Case studies from two 'fagdager'}

As pointed above, the 'fagdag' allowed for a different temporal organisation of the day with access to personal digital devices used and outside school for specific assignments. The aim of the assignments and the restructuring of time and space created an opportunity for constituting and reshaping the educational chronotope. This section explores two incidents of social interaction: one in the traditional data lab and one in a street outside school. Case 1 explores how students reshaped the space and material place inside a formal educational context to make their film about how to solve algebra equations. In the second case, the students used their personal 
digital devices, including SLR cameras and microphones, to shoot films outside the classroom, that is, outside the formal educational context. Both cases contain a chronotopic analysis at the micro level; thus, the unit of analysis is the materiality of the digital devices and the oral interaction during the collaborative talk.

\subsection{Case 1: Shooting a film about equations in the data lab}

During most of the lessons, the teacher explained and demonstrated how to work with a specific math topic, and the students completed assignments individually or in pairs. In other words, the practice of doing math followed a well-known pattern (Franke, Kazemi, \& Battey, 2007). As discovered in the analyses of social interactions in other published studies from the Knowledge in Motion project, the teacher barely created any reference to students' experiences or challenged their engagement (Silseth \& Erstad, 2018; Wiig, Silseth, \& Erstad, 2018), even though there were projects where the students, for instance, worked with wikis (Wiig, Wittek, \& Erstad, 2018). In that sense, the first case contrasted much of the work in math we observed during the fieldwork in the project.

In the first case, the teacher invited the students to create films about how to solve equations. To complete this assignment, the students could work with a computer programme on the laptops provided by the school in the data lab, or they could use their own digital devices. One group, which included Celine, Sara and Silje, had chosen the latter option. Here, how the students reconstituted the educational space in situ is the focus for the chronotopic analysis. Located in the data lab, where they usually used the Geogebra, Kikora and Excel software on the laptops, the students' personal digital devices, such as smartphones, had no specific role. These personal devices could be perceived as boundary objects in traditional lessons because the students negotiated with teachers about when to use them or not (Gilje \& Silseth, 2017). However, in this 
specific project, the students were free to choose what technology to use when completing the assignment. In Excerpt 1, the three students discuss how to reorganise the space to arrange the footage needed for the film.

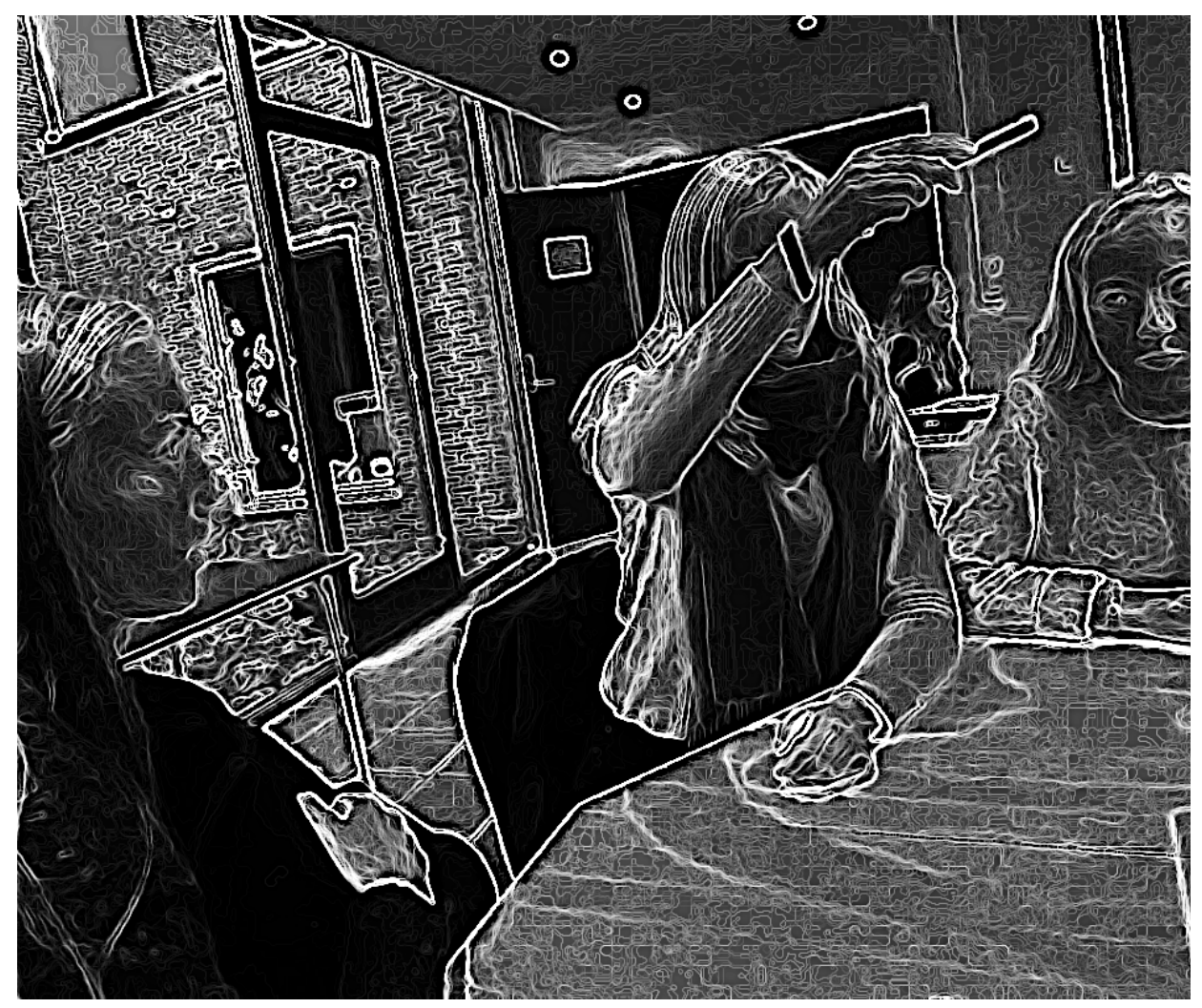

Figure 3. Trying out angles for filming how they solve the equations.

\section{Fxcerpt 1}

1. Celine: We have to find some way to keep the camera in one position.

2. Silje: Yes, I agree.

3. Celine: If we, for instance, put it on the table... [Holding the phone over the table]

4. Silje: This one is high and nice. [Pointing to a tube for cables in the middle of the table]

5. Celine: If we find something ....

Video data, Sørlia, November 2014 
In Excerpt 1, the students struggled with how to use the existing objects to shoot the footage with their phone. Celine poses the challenge in line 1 and adds the position of the camera by holding her phone in the correct position (line 3). In line 4, Silje suggests that the tube for cables, which ran from the ceiling to the table, could be convenient, but Celine does not find that solution good enough, looking around as she utters, 'If we find something...' (line 5).

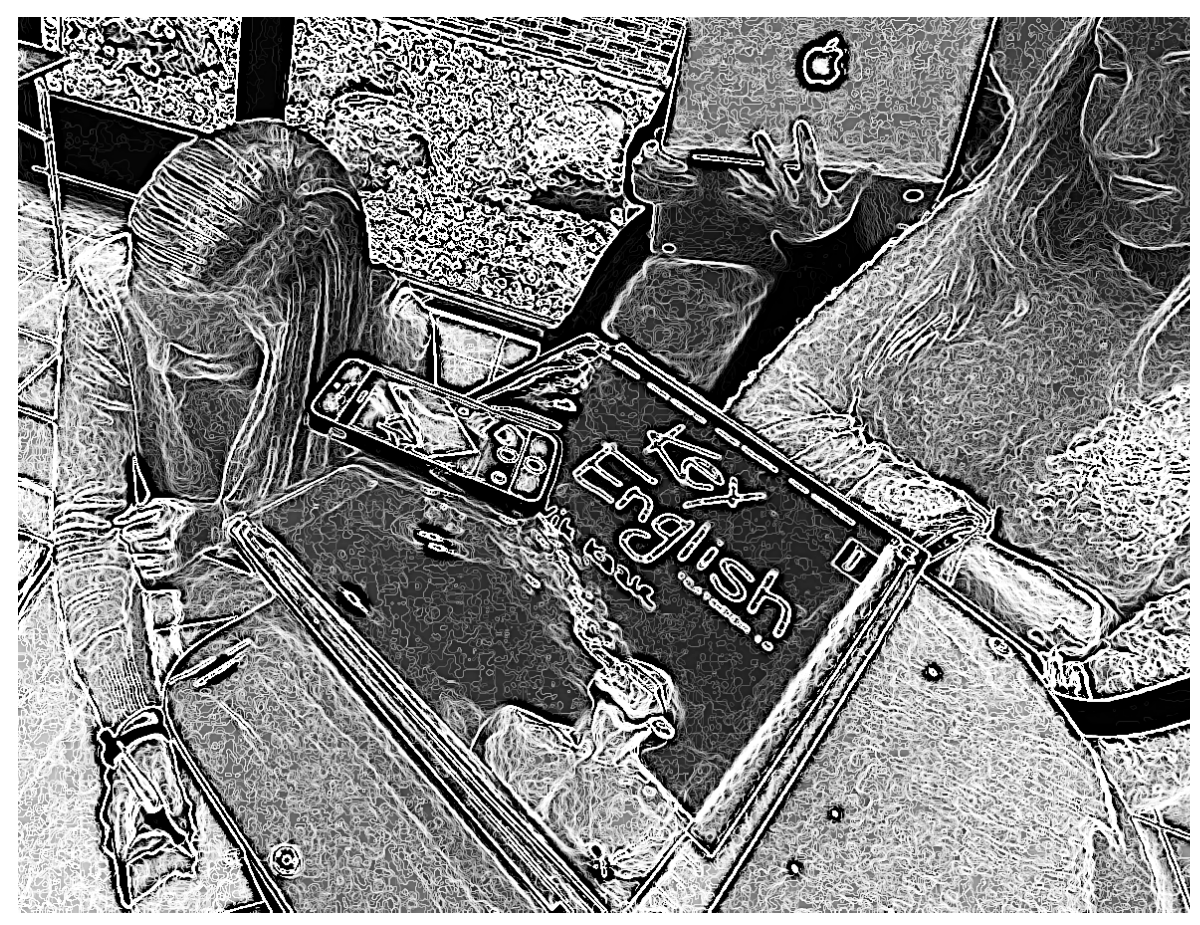

Figure 4. Arranging the shooting using chairs and preparing to edit the video.

\section{Fxcerpt 2}

1. Silje: All this looks very good!

2. Celine: Ok, I am not drawing like ... 
3. Silje: ..... and you must remember to write big enough. Oh, that looks really good. That looks good on camera!

4. Celine: And then I think that this is side A, and this is side B.

Video data, Sørlia, November 2014

In Excerpt 2, the students have found 'something'. The conversation took place as they were trying out the angle for shooting their film. The phone was arranged, the laptops taken away and table and chairs rearranged. In the excerpt, Silje confirms that the phone is arranged in a way that looks good (line 1) and then gives Celine instructions on how to write: 'That looks good on camera!' In the last line, Celine is orienting in the utterance: 'And then I think that this is side A, and this is side $\mathrm{B}^{\prime}$ toward the method for solving equations, with the assignment on the left side and the explanation on the right side. The first case illustrates how the spatial organisation of technology - the data lab in school - allows for certain activities, including sitting at the desk and writing, searching the Internet and doing math on the laptops. The reorganisation of desks and chairs and the use of the students' own personal devices constitute an educational chronotope that allows the students to solve the assignments. They reconstitute the educational chronotope as they use their bodies and artefacts to create a new chronotope in the data lab. By paying attention to both the students' social interactions and bodily movements and reorganisation of artefacts in the room, the analysis can explain how the students create a new educational chronotope inside the traditional educational chronotope, which here is the data lab with its desks, laptops and the cables running down from the ceiling. 


\subsection{Case 2: Norwegian language: Movie-making outside of school}

Case 2 builds on video data from a 'fagdag' assignment in the Norwegian language. Like the students at the beginning of Section 6, these students brought their own digital devices, including a tripod and microphone, to shoot a movie. Often, the students with more competencies and skills in shooting and editing brought their own digital devices to work on the assignment.

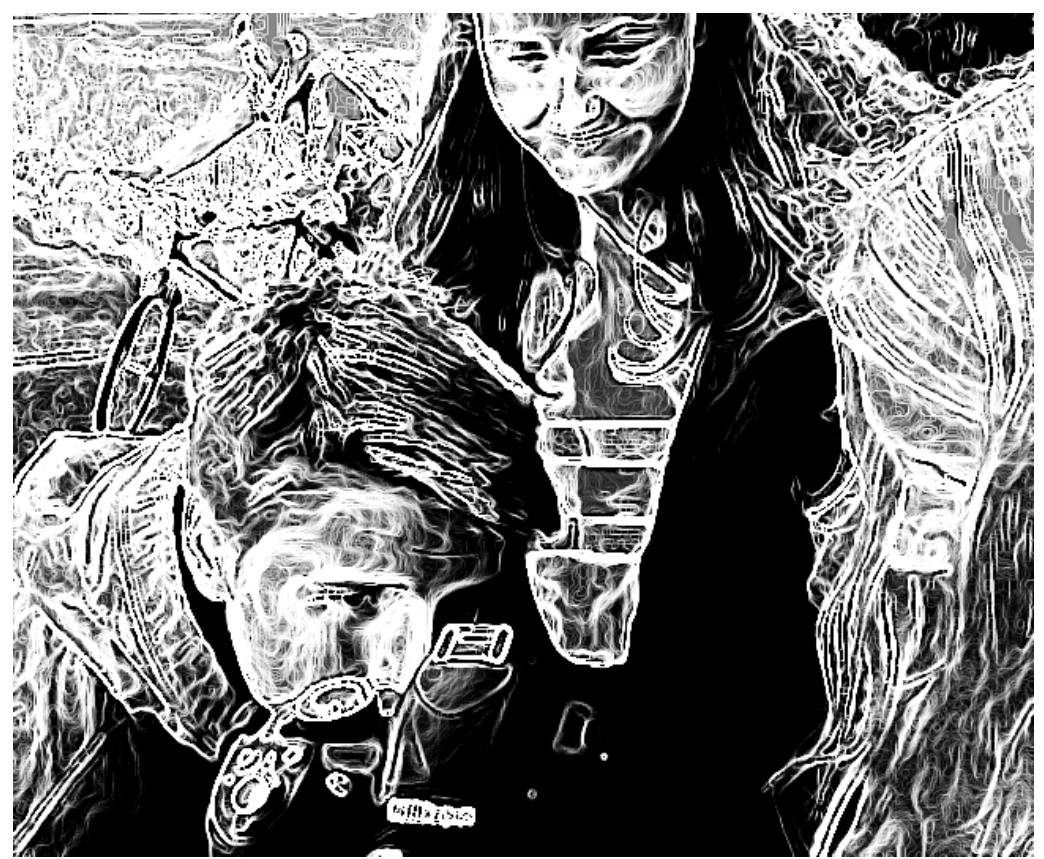

Figure 5. Reviewing the scene for a film about 'why one should use a helmet when bicycling'.

\section{Excerpt 3}

1. Jonas: We have to watch that video if it is good enough. (...) (The three students gather around the video screen on the back of the Nikon camera.) We can only cut you away when you go. (...) There, yes, very good. (The student who did the cycling approaches the other three in the group.)

2. Andreas (bike student): We use it! 
3. Jonas: No, we will shoot it again.

4. Andreas: No.

5. Jonas: Well, we will shoot once more. Come on.

6. Hilde: Was it not good, then?

7. Jonas: Yes, but we need one more. Then we'll have one more to use in editing. Right?

8. Hilde: Yes. (She goes back to her position with the microphone.)

Video data, Sørlia, 1 November 2014

Over the course of the assignment, the students filmed numerous times to create as many clips as possible for editing purposes. In the excerpt, Jonas, who had a lot of experience in filming mountain biking, argues that they needed to have more scenes to choose from. This simple scene discussed in excerpt 3 indicates that students with specific skills used these skills to negotiate and thus manage and direct the work outside of the school context. In Case 2, the artefact structured the activity because the playback of the clip constituted an iterative practice. By watching the clip together, the students use the viewfinder as a mediational mean to share their understanding of how they have succeed with their assignment. As indicated in lines 2 and 3, Andreas and Jonas began negotiating over the scene. In line 6, Hilde asks what was wrong with the clip, and Jonas justifies one more shoot by saying that he needed more footage to work with during the editing process. Hilde was convinced and got into position again, holding the microphone, as shown in Picture 7. In Case 2, the digital technology enabled the students to make judgements about what was 'good enough' for their assignment. In this case, the students constitute an educational chronotope outside of the school context by using the viewfinder on the camera as a reference for their thoughts about the assignment. 


\section{Discussion}

This section returns to the research question: How are educational chronotopes constituted and reshaped when students bring their personal digital technology to solve tasks in specific assignments? In both cases, the students were allowed to bring their own devices to school to solve a specific task. On a meso level, the 'fagdag' activity contrasts traditional schooling, which is structured in spatial and temporal dimensions with its lectures and designated spaces. This restructuring of the lessons and working on one specific task allowed the students to expand the educational chronotope.

The two presented cases have both similarities and differences that can enrich previous research on educational chronotopes. In Case 1, the students created a space with their personal digital devices in the data lab. The spatial dimension of the data lab was challenged and rearranged so that they could use their own digital tools to complete the assignment. In Case 2, the students used personal digital devices outside of the school context to create a space in which they could complete their 'fagdag' assignment. In this way, the chronotopic analysis can shed light on the multiple, and possibly contradictory, space-time contexts that the students produced. In particular it sheds a light on the relation between students every day use of digital technology and school-based experiences and discourses. Such a finding is consistent with findings in other studies of educational chronotopes (Rajala, 2016).

Previous studies on educational chronotopes have provided insight into how digital technology can transform the space-time relationship in educational contexts (Kumpulainen et al., 2013, Rajala, 2016). To further elaborate on how educational chronotopes are reconstructed and shaped, the analysis in the current article explored the relationship between students' interactions and use of personal digital devices. The chronotopic analysis of the organisation and moving of 
objects, bodies and technologies in space and time provides a specific lens for viewing how personal digital technologies constitute a new educational chronotope. An important finding is the role of the viewfinder in case 2 as a mediational artefact for the students' negotiations of the assignment. When it came to framing the shot and reviewing the footage, these actions were facilitated by the digital technology and could be constituted as an iterative practice crucial to the collaborative work on the assignment. In both cases, the analysis reveals the important role of the phone's screen and the camera's viewfinder in structuring time and space in the collaborative work of the assignment - making a film.

An important feature of digital editing devices is the ability to easily review and revise 'text' (Gilje, 2010, 2011). The viewfinder on the camera and the phone's screen became important mediational means for the students' collaborative sense-making. The affordances of the digital technology are related to the ways in which the technology provides an immediate perspective on how the task can be solved. In both cases, the iterative practice of shooting and reviewing the clips was important in seeing whether the students could complete the assignment. In Case 1, the screen on the smartphone was used as a mediational mean to organise the modal affordances for how the students would explain by what means they could solve the equations. In Case 2, the screen was a shared object as the students reviewed the first shoot. The technology constituted and provided an educational chronotope where the students could reflect on whether they had obtained sufficient useful footage for the assignment. In both cases, a chronotopic analysis functions as an examination of how the problem solvers switched between the problem space shaped by oral communication and the problem space shaped by the means of digital technology.

Thus, the present study's findings are in line with those of previous research on digital technology, which has emphasised how digital technology expands educational chronotopes 
(Ritella \& Ligorio, 2016; Ritella et al., 2016, 2017). As noted in Section 2, a chronotopic analysis allows for an explanation of the variations in both the pace and emerging organisation of an activity, or as noted by Ritella and Ligorio (2016), 'The analysis of sense-making helps us to understand the multilevel space-time frames of the collaborative activity' (p. 221).

Although numerous studies using chronotopic analyses have implied a critique of the schooling structure currently characterised by specific lessons and subjects, it is important to note that both new and old chronotopes can coexist in contemporary schooling (Kumpulainen \& Lipponen, 2013; Kumpulainen et al., 2013, Rajala, 2016); this point is particularly interesting when discussing the current study's implications for teachers. As Matusov argued (2015), ‘[An] analysis of educational practices and helps educators better understand what is wrong in conventional school and find new pathways to making schooling an exciting place for learning and teaching. It has both descriptive (in use) and prescriptive (espoused) power' (p. 68). Although many schools are equipped with digital and mobile technologies, the question of how these technologies constitute new educational chronotopes is still an important one. What still needs to be developed is a good set of practices regarding what happens when students use their own technology and how these practices may constitute new educational chronotopes when students are given assignments that can be completed using their own personal, digital devices, such as phones and cameras. The current study's findings can help teachers understand how students can work with personal digital devices in new and innovative ways and by doing so expand the educational chronotope in and outside of the school context. For teachers and teaching, the study inform us how important it is to allow students to work differently with school subjects were their own personal devices can play a vital role in the process of solving the assignments and tasks. The present study's findings are in line with meta-reviews that argued for 
an alternative discourse involving learning-in-place (Erstad, 2014; Leander et al., 2010).

However, there might still be an important point when teaching over the course of the next few decades: these new and novel educational chronotopes can coexist as teachers make more conscious decisions about when and how to use digital technology in school. 


\section{Conflicts of Interest}

The author declares no potential conflicts of interest regarding the research, authorship and/or publication of this article.

\section{Funding}

The paper was written as part of the research project KNOWMO - Knowledge in Motion across contexts of learning, which was funded by The Research Council of Norway [The FINNUT programme, grant number 218262].

Acknowledgements

Because this was a collaborative project, I would like to thank Kenneth Silseth, Ingrid Smette, Åse Strandbu, Kari Stefansen, Camilla Wiig Andersen and Ola Erstad for their support and collaboration during the fieldwork. 


\section{References}

Akkerman, S. F., \& Bakker, A. (2011). Boundary crossing and boundary objects. Review of Educational Research, 81(2), 132-169.

Bliss, J., Säljö, R., \& Light, P. (1999). Learning sites: Social and technological resources for learning. Amsterdam: Pergamon.

Brown, R., \& Renshaw, P. (2006). Positioning students as actors and authors: A chronotopic analysis of collaborative learning activities. Mind, Culture, and Activity, 13(3), 247-259. doi:10.1207/s15327884mca1303_6

Compton-Lilly, C., \& Halverson, E. (2014). Time and space in literacy research. London: Routledge.

Deng, L., Connelly, J., \& Lau, M. (2016). Interest-driven digital practices of secondary students: Cases of connected learning. Learning, Culture and Social Interaction, 9, 45-54.

Erstad, O. (2014). The expanded classroom-Spatial relations in classroom practices using ICT. Nordic Journal of Digital Literacy, 9(01), 8-22.

Erstad, O., \& Smette, I. (Eds.). (2017). Ungdomsskole og ungdomsliv: loering i skole, hjem og fritid. Oslo: Cappelen Damm Akademisk.

Fenwick, T. J., \& Edwards, R. (2010). Actor-network theory in education. New York, NY: Routledge.

Fenwick, T. J., \& Edwards, R. (2012). Researching education through actor-network theory. Malden, MA: John Wiley \& Sons.

Franke, M. L., Kazemi, E., \& Battey, D. (2007). Mathematics teaching and classroom practice. Second Handbook of Research on Mathematics Teaching and Learning, 1(1), 225-256.

Frølunde, L. (2012). Machinima filmmaking as culture in practice: Dialogical processes of remix. In J. Fromme \& A. Unger (Eds.), Computer games and new media cultures: A handbook of digital games studies (pp. 491-507). Dordrecht: Springer Netherlands.

Gee, J. P. (2004). Situated language and learning: A critique of traditional schooling. London: Routledge.

Gilje, Ø. (2010). Multimodal redesign in filmmaking practices: An inquiry of young filmmakers' deployment of semiotic tools in their filmmaking practice. Written Communication, 27(4), 494.

Giljø, Ø. (2011). Working in tandem with editing tools - iterative meaning-making in filmmaking practices. Visual Communication, 11(3).

Gilje, Ø. (2016). Born 1999 - Engagement, participation and learning lives. Paper presented at the Earli Sig Conference, Tartu, Estonia. 
Gilje, Ø., \& Silseth, K. (2017). Mobiltelefonens lange vei fra fritid til skole. In O. Erstad \& I. Smette (Eds.), Ungdomsskole og ungdomsliv: laering i skole, hjem og fritid (pp. 55-73). Oslo: Cappelen Damm akademisk.

Hamilton, D., \& Zufiaurre, B. (2014). Blackboards and bootstraps: Revisioning education and schooling. Berlin: Springer Science \& Business Media.

Hammond, M. (2014). Introducing ICT in schools in England: Rationale and consequences. British Journal of Educational Technology, 45(2), 191-201. doi:10.1111/bjet.12033

Holland, D., Lachicotte Jr., W., Skinner, D., \& Cain, C. (1998). Agency and identity in cultural worlds. Cambridge, MA: Harvard University Press.

Horst, H. A., \& Miller, D. (2012). Digital anthropology. London: Berg.

Ito, M., Baumer, S., Bittanti, M., Boyd, d., Cody, R., Herr, B., ... Tripp, L. (2010). Hanging out, messing around, geeking out: Living and learning with new media. Cambridge, MA: MIT Press.

Jackson, P. W. (1990). Life in classrooms. New York, NY: Teachers College Press.

Jordan, B., \& Henderson, A. (1995). Interaction analysis: Foundations and practice. The Journal of the Learning Sciences, 4(1), 39-103.

Knorr-Cetina, K. (1999). Epistemic Cultures - How the Science Make Knowledge. Cambridge: Harvard University Press.

Kumpulainen, K., Mikkola, A., \& Jaatinen, A.-M. (2013). The chronotopes of technologymediated creative learning practices in an elementary school community. Learning, Media and Technology, 39(1), 53-74. doi:10.1080/17439884.2012.752383

Kumpulainen, K., Mikkola, A., \& Jaatinen, A.-M. (2014). The chronotopes of technologymediated creative learning practices in an elementary school community. Learning, Media and Technology, 39(1), 53-74.

Leander, K. (2001). "This is our freedom bus going home right now": Producing and hybridizing space-time contexts in pedagogical discourse. Journal of Literacy Research, 33(4), 637-679.

Leander, K. (2002). Locating Latanya: "The situated production of identity artifacts in classroom interaction." Research in the Teaching of English, 37(2), 198-250. doi:10.2307/40171622

Leander, K., Phillips, N., \& Taylor, K. H. (2010). The changing social spaces of learning: Mapping new Mobilities. Review of Research in Education, 34, 329-394.

Leander, K., \& Sheehy, M. (2004). Spatializing literacy research and practice (Vol. 15). New York, NY: Peter Lang Pub Inc.

Lemke, J. (2000). Across the scales of time: Artifacts, activities, and meanings in ecosocial systems. Mind, Culture, and Activity, 7(4), 273-290.

Ludvigsen, S., Lund, A., \& Rasmussen, I. (2010). Learning across sites: New tools, infrastructures and practices. New York, NY: Taylor \& Francis US. 
Matusov, E. (2009). Journey into dialogic pedagogy. Nova Science Publishers.

Matusov, E. (2015). Chronotopes in education: Conventional and dialogic. Dialogic Pedagogy: An International Online Journal, 3.

McLay, K., Renshaw, P., \& Phillips, L. G. (2016). iBecome: iPads as a tool for self-making. International Journal of Educational Research. 84, 68-78.

https://doi.org/10.1016/j.ijer.2016.05.009

McLuhan, M. (1994). Understanding media: The extensions of man. Cambridge, MA: MIT Press.

Medietilsynet (2016). Barn \& medier 2016 - 9-16 åringers bruk og opplevelser av medier. Report. Fredrikstad. Norway. Retrieved online 20.9.2018: http://www.barnogmedier2016.no/

Meyrowitz, J. (1986). No sense of place: The impact of electronic media on social behavior. Oxford: Oxford University Press.

Nespor, J. (1997). Tangled up in school: Politics, space, bodies, and signs in the educational process. London: Routledge.

Ott, T. (2017) Mobile phones in school. From disturbing objects to infrastructure in learning. Doctoral thesis. Göteborg. University of Göteborg.

Ott, T., Haglind, T., \& Lindström, B. (2014). Students' use of mobile phones for school work. Paper presented at the International Conference on Mobile and Contextual Learning.Istanbul. Turkey. November, 2014.

Pérez-Sanagustín, M., Nussbaum, M., Hilliger, I., Alario-Hoyos, C., Heller, R. S., Twining, P., \& Tsai, C.-C. (2017). Research on ICT in K-12 schools - A review of experimental and surveybased studies in computers \& education 2011 to 2015. Computers \& Education, 104(Supplement C), A1-A15. doi:https://doi.org/10.1016/j.compedu.2016.09.006

Rajala, A. (2016). Toward an agency-centered pedagogy: A teacher's journey of expanding the context of school learning (Doctoral dissertation). Helsinki: University of Helsinki.

Renshaw, P. (2014). Classroom chronotopes privileged by contemporary educational policy Teaching and learning in testing times. In S. Philipson, K. Ku, \& N. Shane (Eds.), Constructing educational achievement: A sociocultural perspective (pp. 57-79). London: Routledge.

Renshaw, P. (2017). Positionality in researching the dialogic self: A commentary on the possibilities for dialogic theory and pedagogy. Learning, Culture, and Social Interaction. doi:https://doi.org/10.1016/j.lcsi.2017.10.008

Ritella, G. (2018). Chronotope: An investigation of the spatial and temporal organization in technology-mediated collaborative learning (Doctoral dissertation). Helsinki: University of Helsinki. 
Ritella, G., \& Ligorio, M. B. (2016). Investigating chronotopes to advance a dialogical theory of collaborative sensemaking. Culture \& Psychology, 22(2), 216-231.

doi:10.1177/1354067X15621475

Ritella, G., Ligorio, M. B., \& Hakkarainen, K. (2016). The role of context in a collaborative problem-solving task during professional development. Technology, Pedagogy and Education, 25(3), 395-412. doi:10.1080/1475939X.2015.1062412

Ritella, G., Ligorio, M. B., \& Hakkarainen, K. (2017). Interconnections between the discursive framing of space-time and the interpretation of a collaborative task. Learning, Culture and Social Interaction. doi:https://doi.org/10.1016/j.lcsi.2017.08.001

Ritella, G., Rajala, A., \& Renshaw, P. (in review). Using chronotope to research the space-time relations of learning and education: Principles for the unit of analysis.

Roehl, T. (2012). Disassembling the classroom - An ethnographic approach to the materiality of education. Ethnography and Education, 7(1), 109-126. doi:10.1080/17457823.2012.661591

Sacks, H., Schegloff, E. A., \& Jefferson, G. (1974). A simplest systematics for the organization of turn-taking for conversation. Language, 696-735.

Sahlström, F., Tanner, M., \& Valasmo, V. (2017). Some interactional consequences of smartphone use during plenary teaching. Paper presented at the NERA, Copenhagen.

Selwyn, N. (2015). The discursive construction of education in the digital age. In R. H. Jones, A. Chik, \& C. A. Hafner (Eds.), Discourse and digital practices: Doing discourse analysis in the digital age (pp. 226). London: Routledge.

Silseth, K. (2018). Students' everyday knowledge and experiences as resources in educational dialogues. Instructional Science, 1-23.

Silseth, K., \& Erstad, O. (2018). Connecting to the outside: Cultural resources teachers use when contextualizing instruction. Learning, Culture and Social Interaction, 17, 56-68.

doi:https://doi.org/10.1016/j.lcsi.2017.12.002

Silseth, K., \& Gilje, Ø. (2017). Multimodal composition and assessment: A sociocultural perspective. Assessment in Education: Principles, Policy \& Practice, 1-17.

Skaftun, A., Igland, M.-A., Husebø, D., Nome, S., \& Nygard, A. O. (2017). Glimpses of dialogue: Transitional practices in digitalised classrooms. Learning, Media and Technology, 114. doi:10.1080/17439884.2017.1369106

Star, S. L., \& Griesemer, J. R. (1989). Institutional ecology, translations' and boundary objects: Amateurs and professionals in Berkeley's Museum of Vertebrate Zoology, 1907-39. Social Studies of Science, 19(3), 387-420.

Star, S. L. (2010). This is not a boundary object: Reflections on the origin of a concept. Science, Technology \& Human Values, 35(5), 601-617. 
Stefansen, K., Smette, I., \& Strandbu, Å. (2016). Understanding the increase in parents' involvement in organized youth sports. Sport, Education and Society, 1-11.

Strandbu, Å., Stefansen, K., Smette, I., \& Sandvik, M. R. (2017). Young people's experiences of parental involvement in youth sport. Sport, Education and Society, 1-12.

Säljö, R. (2000). Lärande i praktiken: ett sociokulturellt perspektiv. Stockholm: Prisma.

Sørensen, E. (2009). The materiality of learning: Technology and knowledge in educational practice. Cambridge, MA: Cambridge University Press.

Takahashi, T. (2011). Japanese youth and mobile media. In M. Thomas (Ed.), Deconstructing digital natives (pp. 67-82). London: Routledge.

Wertsch, J. V. (1985a). Culture, communication, and cognition: Vygotskian perspectives. Cambridge, MA: Cambridge University Press.

Wertsch, J. V. (1985b). Vygotsky and the social formation of mind. Cambridge, MA: Harvard University Press.

Wertsch, J. V. (1998). Mind as action. New York: Oxford University Press.

Wiig, C., Silseth, K., \& Erstad, O. (2017). Creating intercontextuality in students learning trajectories. Opportunities and difficulties. Language and Education, 1-17.

Wiig, C., Silseth, K., \& Erstad, O. (2018). Creating intercontextuality in students learning trajectories. Opportunities and difficulties. Language and Education, 32(1), 43-59.

doi:10.1080/09500782.2017.1367799

Wiig, C., Wittek, A. L., \& Erstad, O. (2018). Teachers, tools and accountable practices. Engaging with a wiki blog as a learning resource. Learning, Culture and Social Interaction. doi:https://doi.org/10.1016/j.1csi.2018.07.001 